\title{
The Psychiatry of Poverty
}

Addressing a meeting of twenty-five psychiatrists from nine African countries, the UK and the USA at Makerere University College in April 1969, G. Allen German, Professor of Psychiatry, declared that the 'major feature distinguishing psychiatry in Africa from psychiatry in the Western world is poverty'. ${ }^{1}$ Poverty and 'associated ignorance' determined 'many of the peculiarities of clinical states', resulted in inadequate treatment facilities, and interfered both with the use of facilities by patients and with patient follow-up. For German, the 'psychiatry of poverty' entailed a focus not on the types of disorders patients might suffer as a result of poverty, but the ways in which an understanding of poverty might determine the development of mental health services in a particular context. Due to constraints on resources and a lack of manpower in many African contexts, he contended, efforts to develop mental health services needed to focus on the training of non-psychiatrists, whether psychiatric nurses, psychiatric social workers (PSWs), or psychiatric clinical officers. These 'psychiatric auxiliaries' were not only more likely to be drawn from the same areas as their patients, and so speak their languages, but could be trained to take on some of the responsibility for mental health care at minimal cost. ${ }^{2}$

Arguments for the rapid expansion of psychiatry in the late 1960s and early 1970s appeared entirely logical in light of research within transcultural psychiatry and psychiatric epidemiology that was suggesting that the overall incidence and clinical picture of mental illness in Africa

(C) The Author(s) 2019

Y. Pringle, Psychiatry and Decolonisation in Uganda, Mental Health in Historical Perspective, https://doi.org/10.1057/978-1-137-60095-0_5 
was little different from that elsewhere in the world. If anything, pressure on already overstretched psychiatric institutions would only grow in coming years, as urbanisation and other social changes made it more difficult for the mentally ill to be cared for by their families. Like psychiatrists elsewhere in Africa, Uganda's psychiatrists actively contributed to this increasingly transnational and global body of knowledge that was not only challenging many of the earlier assumptions of colonial psychiatrists, but also promising findings that were relevant to changing social and economic circumstances. ${ }^{3}$ One such collaborative study between German and M. I. Assael, an Israeli psychiatrist, along with J. M. Namboze, Uganda's first female doctor, and F. J. Bennett, of the Department of Preventive Medicine, Makerere Medical School, found that among 100 expectant mothers, depressive reactions were common, something 'in keeping with the recent realization that depression is a frequent disorder in the rural African'. ${ }^{4}$ Presenting the results of a study of two hundred and sixty-three pregnant Ugandan women, John Cox similarly argued that the myth that African women were free from emotional disorders during pregnancy was unsubstantiated. Instead, he found similar rates of women with pronounced psychiatric symptoms in Uganda to those reported from studies of European and American women. ${ }^{5} \mathrm{H}$. G. Egdell's research on child psychiatry, meanwhile, was crucial in helping to establish child psychiatry as a serious area of study outside of Europe and the USA. Egdell stressed the similarities in the clinical picture of child neurology with the limited studies already conducted in the USA, India and Nigeria, and made practical suggestions for the development of services for children in developing countries. ${ }^{6}$

By the early 1970s, research by psychiatrists from across developing countries was sufficient to prompt The British Journal of Psychiatry to commission a series of review articles: Carlos A. Leon on psychiatry in Latin America, J. S. Neki on psychiatry in South-East Asia and German on psychiatry in sub-Saharan Africa. ${ }^{7}$ Published in 1972, German's article synthesised two decades of research by African and expatriate psychiatrists that overwhelmingly showed the fallacies of research by colonial psychiatrists. While he noted serious problems with the methodology of some studies, the overwhelming picture of psychiatry in Africa was that of similarity to other parts of the world. The prevalence of mental illness 'seems much the same as elsewhere', he noted: 'schizophrenia, manic-depressive disorder and organic psychoses exist in their familiar forms, although in different proportions; neurotic illness is widespread, although little studied; 
psychogeriatric problems are beginning to appear'. ${ }^{8}$ Where there were differences, they were mainly in behaviour and personality changes, as well as the emphasis placed on physical, as opposed to psychological symptoms. Rather than reflecting racial difference, then, the clinical picture of mental illness seemed to be determined by 'physiological deprivations and physical disease' as well as 'cultural differences and widespread illiteracy'. ${ }^{9}$ As a body of evidence, such ideas about mental illness suggested that provision for the mentally ill in existing mental hospitals was inadequate, but offered no easy answers as to how far psychiatry in developing countries should differ from that in Europe and the USA. Rather, it highlighted the potential strain being placed on a small number of trained psychiatrists, which was only likely to increase in the future. As G. M. Carstairs, President of the World Federation for Mental Health (WFMH), stressed in 1972, what was clear, was that as 'the presence of psychiatric morbidity becomes more apparent' in developing countries, so 'the limitations of medically-trained manpower also come to be recognized'. ${ }^{10}$

The transnational and global context of research was crucial in stimulating the reorganisation of psychiatric services in Uganda. Yet the direction this took, and the ability of psychiatrists to effect change, cannot be separated from the political context of development and nation building. In Uganda, the colonial government had since the Second World War pursued 'development' largely through the 'modernising' projects of state-led industrialisation and the diversification of the agricultural sector. ${ }^{11}$ After Independence in 1962, the Uganda Government, under Milton Obote, similarly prioritised industrialisation, but with a much keener sense of the need to overcome the inequitable distribution of wealth and power, particularly between urban and rural areas. Here, the differences were stark: between 1960-1969, peasants in remote rural areas earned approximately 305-355 shillings a year, $1 \%$ of that of a senior civil servant, and five times less than the average worker in Buganda, in central Uganda. ${ }^{12}$ While the Uganda Government did little to address high government wages, they aimed to combat poverty through an ambitious expansion of social, educational, medical and health services through the 1960s. ${ }^{13}$ The First Five-Year Development Plan (1962) spoke of their intention 'to develop educational facilities on such a scale and in such a way as to provide for every child, regardless of the social or economic circumstances of parents', and 'to provide a comprehensive national health service available to all citizens regardless of means'. ${ }^{14}$ The investment needed to develop services in such a way was prohibitive, 
however, not only financially, but also logistically, as increasing demand for medical and health services strained manpower resources. Pressure on services in urban centres, too, similarly grew as Ugandans flocked to the towns following Independence, putting further constraints on rural development plans. ${ }^{15}$ Here, psychiatry was just one voice at a time when multiple different services were competing for centrality within the development priorities of the nation. Addressing the same meeting of psychiatrists at Makerere at which German had articulated the 'psychiatry of poverty', the Deputy Minister of Health, S. W. Uringi, asked if it was possible 'to so modify traditional psychiatric activity that, by making use of resources which are available in developing populations, adequate services can be provided more cheaply than has been the case in the past?' ${ }^{6}$ Declaring mental hospitals to be an expensive means of keeping people out of sight, he urged psychiatrists to consider other ways of deploying psychiatric personnel: 'What level of training do they require? What facilities do they need? What resources already exist in the community which can be utilised and adapted to minimise expenditure? 17

During the late 1960s and early 1970s, psychiatry flourished in a period of experimentation and innovation intended to extend the reach of psychiatry at minimal cost. Uganda's psychiatrists established a Mental Health Advisory Committee (MHAC) with the aim of advising the Ministry of Health on policy and lobbying for reform. They discussed and trialled proposals to train PSWs, interpreters and psychiatric clinical workers, and to establish mental health clinics in hospitals where responsibility would be delegated to non-specialists. Recognising that they needed not only to persuade government officials, but other professionals - health, legal and welfare- of the need to take an interest in mental health, they combined pilot schemes with mental health education programmes. They set up Africa's first National Association for Mental Health (the NAMH), launched training courses for police officers, lawyers and health workers in hospitals outside of Kampala and participated in a television series entitled 'The Sick Mind'. These activities aimed not only at spreading Western ideas about mental illness to the wider Ugandan public, but to mobilise supportive professionals in order to extend the reach of psychiatry beyond that which could have been achieved by psychiatrists alone.

This period of relative political stability in Uganda's history since 1962 was one of a new contextually sensitive politics, and it was one that demanded the refiguring of the relationship not only between 
psychiatrists and patients, but also between psychiatry and other institutions and services. The newly independent Uganda Government was accountable to its citizens in ways that the colonial government never had been, and psychiatrists were well aware of the need to demonstrate the relevance of their work. In this, many of Uganda's psychiatrists benefitted from their association with Makerere Medical School, which during the 1960s became an internationally renowned centre of research and practice, attracting over $£ 280,000$ in medical research grants between 1964-1967 (approximately 5 million pounds in today's terms). ${ }^{18}$ Yet psychiatry nevertheless faced ongoing practical constraints on its ability to translate rhetoric and small-scale experiments into real, felt change 'on the ground'. Much of this was beyond the control of the psychiatrists. Indeed, it proved impossible, logistically and financially, to train sufficient specialist personnel in such a short period of time. Similarly, the scale of the task of moving psychiatry away from a system that continued to bring only the most 'urgent' or violent patients to the gates of Butabika Hospital was overwhelming. But equally, the limits to reform might be best understood as a failure to fully consider the needs and priorities of the patients themselves.

\section{Problems of Social and Economic Change}

Research in the field of mental health may have formed part of a broad transnational endeavour to show that the clinical picture of mental illness was little different in Africa to that elsewhere, but much of it was driven by concern about two key features of social and economic change in early postcolonial Uganda: education and urbanisation. Education provision had expanded rapidly in the final years of colonial rule, with double the number of pupils attending primary school and eight times the number of students in secondary education by $1962 .{ }^{19}$ Expansion continued through the 1960s, with education positioned as essential not only for economic growth, but also for the well-being of the nation. ${ }^{20}$ Urbanisation, too, accelerated across East Africa after Independence, as rural migrants moved to cities in search of work, adding to the growth of an informal sector and posing challenges to municipal order. ${ }^{21}$ These changes brought students and urban residents to the forefront of psychiatric attention and provided an important way of demonstrating the relevance of psychiatry in a new sociopolitical context. As Bennett explained in 1967, students at Makerere faced a series of unique stresses. 
'The majority', he noted, 'are the first generation of the educated. Great expectations rest upon their shoulders. For most, arrival at Makerere means a sudden change from a traditional, family centred way of life to the novel freedoms and restraints of a European patterned centre of learning set in the forefront of the intellectual, political and technological revolution of mid-20th century Africa'. ${ }^{22}$

In 1969, German, together with O. P. Arya, of the Department of Preventive Medicine, undertook a study of psychiatric morbidity among students at Makerere University College. 'This student population', they noted, 'is of peculiar interest to psychiatrists, partly because it is predominantly African, but also because these African undergraduates occupy a central position in the whirl of social and cultural changes sweeping across East Africa'. ${ }^{23}$ While German and Arya found no evidence to suggest that mental illness was on the increase at Makerere, they argued that the rate of mental breakdown was relatively high: of 1112 attendees to the Student Health Service, 121 (10.8\%) were found to be suffering from a psychiatric disorder-mostly anxiety and depression. ${ }^{24}$ Students reported overwhelming stress relating to examinations and study, fears of having contracted venereal disease, as well as anxiety about the size and potency of their genitals (the last two perhaps unsurprising given the high incidence of gonorrhoea on campus). ${ }^{25}$ Yet among these students, at least two were surprised that their accounts of their emotions, which included feelings of worthless and suicidal ideas, had led them to be referred to a psychiatrist for depression. ${ }^{26}$

Research on student mental health reinforced wider concerns about the effects of the expansion of education through the 1960s. This was not because it was believed that the stresses of 'western' education in itself would in some way lead to mental breakdown, however. Indeed, in this way, the research in Uganda differed from that of Raymond Prince on 'brain-fag syndrome' among unmarried adult Nigerian males studying in England. This constellation of complaints, which was marked by intellectual impairment, sensory impairment (chiefly visual), and somatic complaints most commonly of pain or burning in the head and neck', was, Prince hypothesised, 'in some way related to the imposition of European learning techniques upon the Nigerian personality'. ${ }^{27}$ Instead, German and Arya offered a social and psychological explanation for the relatively high rates of mental illness seen among East African students. For them, it was unsurprising that students might break down while studying, given 'the enormous emphasis placed on academic success by families and society' ${ }^{28}$ 
The social aspects of urbanisation were similarly stressed by researchers who looked towards the growing number of migrants moving to Kampala-often living alone and in poverty. ${ }^{29}$ Many came from rural areas, contributing to an increase in population in Buganda of approximately 40\% between 1949 and 1958. But one of the most striking features of Uganda was the high level of international migration from neighbouring African countries, comprising approximately $10 \%$ of the population by the early 1960s. ${ }^{30}$ Immigrants from Rwanda, who were increasingly moving away from the border area in south-west Uganda in search of employment opportunities, were of particular concern: by 1966, Rwandan immigrants comprised approximately $4.5 \%$ of the population of Kampala, with many having first entered Uganda during the 1959-1964 Tutsi refugee crisis. ${ }^{31}$ Rwandans were also the fastest growing group of inpatients at Butabika Hospital, comprising over $10 \%$ of first admissions in the first half of $1968 .{ }^{32}$

Despite the refugee background of some of these immigrants, no link was made between violence and psychological health. Indeed, as we shall see in Chapter 7, the notion that refugees might have unique mental and psychological needs as a result of their exposure to violence, and ongoing uncertainty about their futures, was rarely considered in Africa before the 1980s. Instead, as Bennett and Assael contended in 1970, their presence in the psychiatric system was due to a 'changing society' that not only made mental health problems more visible, but was leaving increasing numbers of individuals without adequate social support networks. As one Rwandan living near Kampala commented, while he had not been rejected by his neighbours, he still felt isolated: 'No-one will help if something happened'. In a comment that points to disconnects between expectations and reality, another complained: 'I am disappointed with friendship here where no one will help unless you pay - this is not Rwanda'. ${ }^{33}$ Bennett and Assael reported finding high levels of alcoholism, depression and anti-social behaviour among the Rwandan immigrants they studied living near Kasangati Health Centre. Yet it was immigrant children for whom they expressed the most concern. In addition to having parents 'caught in a web of depression, alcoholism and isolation', school- 'the one institution which would help in fitting them into the new society' - was out of reach due to the inability of their parents to pay fees. If support measures were not set in place, they added, 'A frustrated and delinquent second generation might evolve' 34 
Psychiatric research presented a coherent view of how social and economic changes were shaping present and future mental health needs. But the voices and opinions of those under the psychiatric gaze were obscured within it, not only in terms of descriptions of their symptoms, but whether their problems were psychiatric or social in nature, and how they might best be helped. The comments of the two students who were 'surprised' at being diagnosed with depression hint at this. But undergraduate students at Makerere in particular had their own ideas about the problems of education. They were, for example, acutely aware of their isolation on the campus at Makerere University College which, despite being located on the edge of Kampala, was 'still basically a community fenced in, with a gate guarded day and night, an appearance of social exclusiveness'. ${ }^{35}$ The weight of the institution and its expectations also weighed heavily on their minds, not only as a result of the lengthy 'filtering process' of national examinations that had selected them as an elite group, but through the way the institution unwittingly forced students to choose between 'the West' and their cultural roots. ${ }^{36}$ As Peter Nazareth, Ugandan literary critic and Makerere graduate recalled: 'There was a heavy colonial pall over the place which made it quite hard to be creative instead of imitative, to challenge any of the norms. I mean, we were supposedly the elite who had made it up there and yet somehow there was this feeling that we were not good enough. We were not European'. ${ }^{37}$ While the curriculum was changing during the 1960s, with increased recognition of the importance of African history and literature, among other subjects, Makerere as an institution was still heavily Europeanised. ${ }^{38}$ Much of this found expression in East African literature during the 1960s and 1970s. The journalist-protagonist of John Nagenda's 'And This, At Last', written while an undergraduate, is a product of a colonial school education and demonstrates a condescending attitude towards village life. Yet after interviewing an old man, his superficiality is shattered: the journalist and fellow graduates are 'doomed to sterility and civilization'. ${ }^{39}$ In Jonathan Kariara's poem, 'The Dream of Africa', moreover, similarly written while at Makerere, Kariara described how the 'white clay of foreign education' was 'stifling' the African. Critiquing the cultural dependency created by education (and indeed medicine), Kariara wrote of the anxieties arising from what was essentially a reworking of the self: 
Doctor, what ails me, what ails -

(The bottled ale I took the other night to forget)

The ready-made pill prescription

For a slight mental maladjustment

Due to...due to...that's not for us to know:

It is the knowing doctor's secret.

"Business, you see."

So we glibly take it, the pill,

Which smoothes the pain and smoothes the nerves,

And sends the disease to sleep.

Even then, despite all expectations, there was no guarantee that this preparation was not all for nothing when the 'white clay' was removed: 'Will it be the pearl in the oyster shell, / Or mere rottenness?' Makerere graduates would have agreed with the psychiatrists that it was not 'education' per se that was a problem, but would likely have had very different ideas about the nature of changes required. Rather than seeing their experiences as indicative of the need for an increase in the capacity of mental health services in Uganda, it was the approaches, values and content of education that needed to be addressed.

Analysis of the problems facing students and urban migrants pointed to a need for wide-ranging reforms not only within education, but in the provision of social welfare services. Yet psychiatry's interest in these groups did not translate into additional, targeted psychiatric support. While from 1966 psychiatrists ran a monthly clinic at Kasangati Health Centre, an area with a relatively high number of migrants, as well as individuals living alone, there was no specific service for Rwandan immigrants, and no psychiatrist who could speak Kinyarwanda. ${ }^{41}$ At Makerere, too, students seeking assistance for anxiety and depression continued to rely on the Student Health Service which, reflecting the insular nature of the campus, was used by an estimated $80-90 \%$ of all students in any one year. ${ }^{42}$ The medical practitioners who staffed the service had no specialist training in mental health, their main role in these cases being to counsel students. The small number of students who showed signs of schizophrenia or psychosis were referred to a psychiatrist at Mulago Hospital, but otherwise mental health was handled internally, and there were no plans to increase or change this service. ${ }^{43}$ The importance of concern about education and urbanisation should instead be located in the way it provided a bridge between psychiatry 
and the needs and priorities of the developmentalist state- a way of demonstrating psychiatry's relevance to both state and society. In an attempt to combat the long-standing neglect of psychiatry by government officials, the psychiatrists of the late 1960s and early 1970s would use it to point to signs of growing pressure on medical, health and social welfare services in the future.

\section{Psychiatry and the Development of Health Services}

Like many other African countries, Uganda inherited a health system from the British in which care was concentrated in large, predominantly urban hospitals. The expense required to maintain this health system was staggering, constituting as much as $70 \%$ of government expenditure in the years between Independence in 1962 and Idi Amin's coup in $1971 .{ }^{44}$ Instead of focusing on the development of basic health services, the newly independent Ministry of Health maintained this highly centralised system, prioritising the expansion of central referral hospitals (including the completion of Butabika Hospital and a state-of-the-art New Mulago Hospital), then district hospitals and, on a much smaller scale, rural health clinics. ${ }^{45}$ The high capital expenditure required by this development strategy went against World Bank policy (which Uganda abandoned in 1964) and was subject to fierce criticism by medical practitioners, but it pleased voters and their demands for more hospitals. 'The cry by every Ugandan', Minister of Health Emmanuel Lumu exclaimed in 1970, is 'more hospitals, more dispensaries, more aid posts, more medicine and so on'. But, he added, 'I am afraid that we cannot keep up with the demands of the country' ${ }^{46}$ Rural populations continued to be under-served, not least by psychiatry, where there were still few specialist personnel and the mental health services in Kampala were remote.

The MHAC, established in early 1967 by German, set itself an ambitious goal: they aimed to convince the Ministry of Health to aim for mental health to comprise $25-30 \%$ of the national medical effort at all levels-beds, staffing and budget. This figure presupposed a growing need in the coming years as investments in public health and preventive medicine reduced rates of physical illness and made mental illness more visible. While they could not claim that voters were demanding new psychiatric services, they argued that the pressures brought on by education and urbanisation, as well as the 'increasing burdens of responsibility' placed on the workforce, was 'accelerating the demand for psychiatric 
treatment many times over'. ${ }^{47}$ Above all, the MHAC wanted to overcome the lack of investment and interest in psychiatry since the colonial period. In line with more general investment in district hospitals, the Ministry of Health had made provisions for eight 16-bed psychiatric units in their Second Five-Year Development Plan (1966), but the MHAC saw this as a potential 'embarrassment to the psychiatric services'. In an official statement to the Ministry of Health in 1967, the MHAC expressed their dissatisfaction, arguing that 62 -bed units with outpatient facilities, and staffed by a doctor and 'a proper psychiatric team' of nurses and social workers, were instead necessary to meet growing demand. While in the past 'priorities in the field of mental health have been overlooked', the MHAC hoped that things would soon be remedied. ${ }^{48}$

The MHAC represented an official collaboration between psychiatrists employed by Makerere University College and those employed by the Uganda Government. Sanctioned by the Ministry of Health, this advisory body comprised of Ugandan and expatriate psychiatrists, as well as other individuals with an interest in the development of mental health services. ${ }^{49}$ While in 1967 the MHAC was small, consisting of German, Stephen B. Bosa, James F. Wood, and a medical officer, mental nurse and matron attached to Butabika Hospital, by 1971 it had expanded to include psychiatrists, mental nurses, a high court judge, a police commissioner and members of the Ministry of Health. ${ }^{50}$ The MHAC worked closely to advise and implement new plans for the extension of mental health services, lobbying the Ministry of Health for financial support, when necessary. Members of the MHAC also investigated and prepared papers on a range of topics, opening up a dialogue between psychiatrists and the Ministry of Health on such themes as interpreters and the Uganda Psychiatric Service, psychiatric social work and trial mental health clinics at Jinja and Mbarara Hospitals. ${ }^{51}$ The discussions highlighted a range of opinions and suggestions as to what should take priority, yet all aimed at extending the reach of psychiatry at a time of increasing pressure on government finances.

Despite their ambitious goals, the MHAC experienced many of the same frustrations that Bosa had earlier in the decade when he had approached the Ministry of Health with suggestions for reform. One of the earliest proposals to meet with failure was that for an official cadre of interpreters in psychiatric service. A briefing note written by Egdell described the language barrier that was preventing adequate communication between patients and staff, as well as contributing to an 'unpleasant 
isolation' of many inpatients. Highlighting the contingent nature of psychiatry, Egdell noted that 'Without an interpreter the psychiatrist is in the same position as a blind physician, unable to see physical signs' ${ }^{52}$ Beyond English, Luganda and Swahili, knowledge of most of Uganda's fifty-plus languages was almost non-existent among expatriate and Ugandan psychiatrists, ward sisters, PSWs and medical students who, coming from across East Africa, 'often cannot even speak Luganda'. ${ }^{53}$ The ability of nursing staff to converse at a basic level was not enough, as Egdell stressed: 'We need precise details of subtle changes in thinking, feeling and behaviour which are often expressed in African languages with the greatest difficulty'. ${ }^{4}$ The MHAC therefore proposed to the Ministry of Health that an initial group of twenty-five interpreters be trained to cover Mulago and Butabika Hospitals, psychiatric social work, social and occupational therapy, and the courts. Within a year, however, the plan was dropped. In addition to the administrative difficulties of introducing a new cadre of staff at a time when the Uganda Government was streamlining the civil service, there were questions of cost, training and delegation. The interpreters would require 'an understanding of psychiatric, psychological and medical terminology in English and the other languages mentioned above, appreciating the significance of these terms in relation to indigenous languages and customs', yet who could ensure their accuracy? 55

The inflexibility of the Ministry of Health was again seen in response to plans to train a new cadre of PSWs. A two-year scheme proposed by Bosa and F. J. Harris, World Health Organization (WHO)-supported Lecturer in Psychiatric Social Work, the proposal was intended as a way of bolstering follow-up and family outreach in district hospitals. PSWs would take social histories from patients and relatives, explain diagnoses and methods of treatment, prepare families to receive patients after discharge and be responsible for after-care, counselling of parents and mental health education in rural communities. These duties were 'arduous and time-consuming' but considered necessary to ensure the functioning of psychiatry beyond Butabika and Mulago Hospitals. ${ }^{56}$ With financial support from Makerere, Harris started training a small number of PSWs, but the Ministry of Health refused to recognise the Diploma in Psychiatric Social Work. Just as with the interpreters in psychiatric service, this new cadre required the creation of a new position within the civil service, and with it, new administrative and financial obligations. 
With a Ministry of Health that was reluctant to commit to large, potentially costly schemes, the MHAC focused on small pilot projects, funded jointly by Makerere and the Ministry of Health, and aimed at exploring how mental health services could be best developed at minimal cost. In 1968, E. B. Ssekabembe launched a Jinja Mental Health Follow-up Clinic trial, to operate every last Friday of the month. ${ }^{57}$ In the first few months of operation, between 5 and 11 patients attended the clinic each month and received medication on an outpatient basis, including sedatives (such as Largactil) and anticonvulsants (such as Phenobarb). Yet with Jinja Hospital failing to release a medical officer (MO) to assist Ssekabembe once a month, it proved impossible to train anyone to take over the clinic. Added to this were medical assistants at Butabika Hospital who had 'forgotten' to advertise the clinic. Reflecting a recurring gap between intentions and the ability to transform practices and behaviours, one patient complained that the clinic had not been well advertised at all, and pointed to over 20 cases in his village, near Jinja, who were in need of help. ${ }^{58}$ Demand for a clinic was also evident in a trial at Mbarara Hospital, which Bosa operated once a month, hoping that 'perhaps with luck one might stimulate enough interest in some doctors for them to devote more attention to the understanding and care of the mentally sick'. Between 14 and 24 patients attended each month in the first six months, with one MO, B. Kahigwa, requesting further training at so he could take over the running of the clinic. Despite similar problems in advertising their work beyond a small area around the hospital, Bosa called the trial a resounding success: not only had it reduced the number of referrals and readmissions to Butabika Hospital, but the 'physical appearance of a consultant psychiatrist at the hospital helped to improve the attitude towards mental illness, management and treatment in both staff and patients, and also in the general community'. ${ }^{59}$ In the coming months, Bosa added, he was confident he could 'demonstrate convincingly (with figures)' that Ministry of Health investment in mental health at Mbarara 'is now essential and very urgently required'. ${ }^{60}$ Well aware from his own previous experiences of the difficulties of persuading government administrators for support, Bosa knew he not only had to draw up a careful case for funding and personnel, but be wary of how he presented any practical difficulties experienced.

While the pilot mental health clinics, operating every four to six weeks, did not represent a huge time commitment in and of themselves, they nevertheless required seemingly endless energy from those involved. 
After a full week's research, teaching and clinical duties, German would on a Friday once a month drive to Soroti, 300 miles north-east of Kampala, check into a hotel and be ready for work at a mental health clinic at Soroti Hospital by seven o'clock the following morning. On the Sunday, German would then devote three to four hours delivering a case conference and lecture series to senior nursing staff, MOs and any other interested parties, before driving back to Kampala. Bosa, too, would travel to Mbarara and other district hospitals after a full week's work, dedicating his Saturdays to clinical work, court work and the training of medical and health workers. ${ }^{61}$ In addition to the personal drain of this work, there was ongoing frustration at the slow pace of change, as well as fears that activities that took staff away from Butabika Hospital were contributing to an increasing reliance there on psychotropic drugs. ${ }^{62}$ Indeed, despite the relatively large number of psychiatrists in Uganda in the late 1960s and early 1970s, pressures on time meant few practical changes to conditions at Butabika Hospital. As John Orley noted: 'Doctors in a hospital admitting over 60 patients a week, and who usually do not speak the patient's language find it almost impossible to do more than give rough symptomatic treatment with medication and E.C.T., and sometimes do not bother with the niceties of diagnosis'. ${ }^{63}$ By the end of 1968, Bosa had decided to relinquish his research and teaching responsibilities at Makerere and to return to primarily clinical work, stressing that he 'would have better immediate opportunities to utilize my potential abilities' at Butabika Hospital. ${ }^{64}$

The early experiences and setbacks faced by the MHAC made it clear that while increased investment, improved facilities, and new specialist training programmes was the ideal, financial and administrative constraints meant they could only work with existing resources, of which 'manpower', as it was called, was considered to be the most valuable. ${ }^{65}$ Training new psychiatrists was not only costly but also time-consuming, offering little chance of expanding psychiatry in the short term. Medical assistants, on the other hand, already existed in relatively large numbers, being regarded as the front line of health care provision in rural areas. ${ }^{66}$ Based on his observations at Soroti, German estimated that one in five psychiatric cases went in the first instance to general hospital outpatient clinics, where they were attended to by medical assistants. ${ }^{67} \mathrm{In}$ district hospitals, according to Egdell, medical assistants took on work with inpatients that was similar to that of an intern: 'Histories are taken and initial provisional diagnosis [sic.] are made'. ${ }^{68}$ It was in outpatient 
departments and rural dispensaries that their value was truly felt, however. There, they saw all patients in the first instance, selecting from them five per cent who needed to be seen by an MO. 'The remaining 95\%', Egdell noted, 'are independently diagnosed and treated by the medical assistant himself' ${ }^{69}$ In rural dispensaries, moreover, medical assistants were in sole charge, overseeing 25-30 inpatient beds, in addition to fifty or more outpatients a day. As such, they represented untapped potential for mental health care. "[The] medical assistant fully trained in psychiatry', Egdell stressed, 'would become a member of the psychiatric team up-country or possibly in the national mental hospital. Whilst continuing in their traditional role as equivalent to house officer or intern, they would also provide continuity in psychiatric leadership in the inevitable absences of the psychiatrist' ${ }^{70}$

The training of medical assistants in psychiatry was not uncontroversial. Concerns were raised, for example, that while medical assistants saw hundreds of patients every day in outpatient departments and dispensaries, requiring them to be on the lookout for cases of mental illness would potentially 'put too much load' on them. While most patients would likely be non-violent, personal safety would also need to be considered, as too would the implications for the profession of assistants taking on sole responsibility for both diagnosis and treatment. ${ }^{71}$ Despite these concerns, 'there was unanimity' among the MHAC 'that some form of training should be given to medical assistants'. ${ }^{72}$ Bosa and Ssekabembe provided a small amount of informal in-service training in psychiatry to medical assistants in district hospitals during their visits, highlighting their value in being able to speak patients' languages and understand local cultural idioms of madness. ${ }^{73}$ In June 1969, moreover, German, J. W. S. Kasirye, Bosa, Wood, Assael, and Ssekabembe submitted a memo to the Ministry of Health setting out potential options for the training of medical assistants in psychiatry, including an eight-week practical course based at Butabika Hospital. 'With appropriate training', it was hoped, the medical assistant would be able to diagnose patients, the majority of whom presented only 'with vague somatic complaints', and in many instances treat them successfully. ${ }^{74}$ The proposal, meeting the Ministry of Health's position that any changes require minimal administrative or financial implications, was accepted by the Uganda Government and Makerere University College. By 1971, medical assistants were receiving 'comprehensive teaching in basic psychology' in the first year of their training, and plans were underway to include clinical psychiatry in the second and 
third years. ${ }^{75}$ This model of training and delegating responsibility would come to be recognised internationally as the defining feature of psychiatry in Uganda.

\section{Mental Health Education}

With the number of trained medical assistants remaining small until well into the 1970s, and the number of PSWs almost non-existent, in most areas there was still almost no outpatient or after-care available for those seeking relief from mental distress. One nurse who worked at Kabale Hospital, in south-western Uganda, in the late 1960s and early 1970s, described her frustration at the limited assistance they could provide to patients who came to their doors. While the hospital did at times have a small supply of Largactil, it was kept in a locked box, closely guarded by the sole doctor who had been trained to dispense it. With little else to offer, they sent most patients away. ${ }^{76}$ The inability of psychiatry to effect widespread, practical reforms in the short term also meant little change to admission patterns at Butabika Hospital. As under colonial rule, violence remained a recurring reason for admission, being the main cause in approximately half of all cases in 1968. ${ }^{77}$ Pressures on time, as well as difficulties in communication, also meant that diagnoses continued to be made with limited information, and reflected behaviour observed in the period immediately leading up to admission. One man, who had long history of 'behaving and talking strangely and aggressively', had problems sleeping, and so relied on an alcoholic sedative-1/4-1/2 pint of spirit, distilled from banana beer. Rarely violent, his behaviour was suggestive of an underlying psychological disorder, yet when he suddenly became violent, prompting his being taken to Butabika Hospital, he was diagnosed with 'alcoholic confusional state', and treated by sedation with phenothiazines, before being released home shortly after. ${ }^{78}$ Also in line with earlier trends, the number of admissions continued to rise at Butabika Hospital, reaching 3036 between July 1967 and June 1968, with pressure on accommodation meaning that most needed to be discharged within eight weeks. ${ }^{79}$ The dangers of the increasing pressure to discharge patients without adequate provision for follow-up support were made painfully clear in 1970, when a policeman, recently released from Butabika Hospital and certified fit to return to work, shot dead the Manager of Mwenge Tea Growers Estate in a fit of confusion. ${ }^{80}$ 
The MHAC were aware of such problems, but unable to train a cadre of psychiatric auxiliaries overnight, they instead stressed the importance of mental health education as a way of mobilising other professionals to fulfil their legal and social responsibilities towards the mentally ill. In light of the colonial legacy linking psychiatry with violence, police officers were given special attention in attempts to reform psychiatry. 'If he is to do his work well in this field', as Wood noted, 'he needs to have some of the skills of the psychiatric social worker, the psychiatric nurse and the psychiatrist'. ${ }^{81}$ In a lecture to lawyers, moreover, Wood explained the main symptoms, treatment and legal considerations of personality disorders, as well as illness caused by organic or physical diseases, schizophrenia and manic-depressive psychosis. ${ }^{82}$ Reflecting an increasingly dominant trend within transcultural psychiatry, he stressed that mental illness was both universal and shaped by culture, something that had relevance to the interpretation of the law. Hallucinations, he noted, were 'very real to the subject':

People with spears, lions and snakes come through windows and doors and crowd round him on the bed. He can hear people talking, threatening and abusing him. Such subjects may jump through the window to escape their hallucinatory persecutors or may unfortunately pick up the ever ready panga from below the bed and "defend" themselves. Usually this results only in a chair being chopped up for a lion but occasionally and tragically a child, a father, mother or brother may be standing by the bedside and may be the victim. ${ }^{83}$

Such a description was reminiscent of earlier colonial interest in the content of 'native' delusions, but was framed here in more culturally sensitive terms.

In educating lawyers about mental illness, Wood took on something of a social advisory role, commenting on social problems that he felt could be more effectively dealt with by increased treatment services and possible changes in the handling of the law. Homosexuality was one such issue. In line with psychiatric thinking in Europe and the USA in the late 1960s, Wood defined homosexuality as 'a sexual perversion resulting from a personality disorder' ${ }^{84}$ While psychiatrists in colonial Africa had had little to say on the subject of homosexuality, seeing it, along with transvestitism and paedophilia, as extremely rare, ${ }^{85}$ the effects of negative attitudes towards homosexuality had been raised as a problem in more 
recent research on student mental health. ${ }^{86}$ Changing attitudes towards homosexuality, according to Wood, stemmed directly from legislation introduced under colonial rule. ${ }^{87}$ The Penal Code criminalised homosexuality as an 'unnatural offence', placing it alongside bestiality. Any person found to have committed the offence could be charged with a felony and be liable for up to seven years in prison. ${ }^{88}$ While only a few men were imprisoned under this legislation-one in 1956, four in 1959 and one in 1960, for example-the law was regarded as having potentially long-term ramifications. ${ }^{89}$ Referring to 'homosexual acts between consenting adults in private', Wood argued that it would appear that the '(male) homosexual has been debarred from exercising personal liberty in the matter of sexual practice and that such legislation might be seen to contribute to the causation of mental illness in that it directly (and indirectly by influencing social attitudes) increases the psychological stresses the homosexual must overcome'. ${ }^{90}$ For Wood, the homosexual was not only suffering from a sexual perversion, but at risk of serious mental illness from outside pressures-from punitive legislation and social attitudes that were shaped by it. While Wood did not explicitly request that lawyers attempt to seek changes in the law, he emphasised that it was only those homosexuals who engaged in sex with minors who should be considered as a serious problem for society, as this 'might tend to mould them also to the same sexual habit' ${ }^{91}$

Building on the success of such lectures, Wood negotiated funding from the Uganda Government for a training course on mental health for police officers. ${ }^{92}$ Wood's topics included a history of psychiatric services in Uganda, the state of contemporary mental health provision, as well as the signs and symptoms of different types of mental illness. Describing a situation that could have been applied to Uganda at any point during the last forty years, he stressed that officers in rural areas 'may have to look after some very sick patients for several days and may have difficulty in getting medical attention for the patient.... They may have difficulty coping with excited patients who may tend to become violent.... They may have difficulties with patients who refuse food and fluids.... They may find that if they put mentally ill patients together without someone to look after them that the patients may harm each other'. ${ }^{93}$ Police officers, Wood stressed, had to recognise their vital role in mental health services, not only in identifying whether a person required medical treatment or restraint, but also in acting 'as transporters, minders and providers until the mentally ill person could be safely delivered to Butabika Hospital or 
to the Mulago Hospital Psychiatric Outpatient Centre'. ${ }^{94}$ The police already required many skills usually filled by social services-now 'psychiatric patient management' had to be another. ${ }^{95}$

The 'public' targeted through such seminars and lectures was limited to 'interested' professionals, and they found, time and again, that they were required to fight against a broad 'public apathy' to mental health activities. ${ }^{96}$ This was no less the case with responses to the NAMH, founded in 1967 under the leadership of Bosa and German. ${ }^{97}$ The $\mathrm{NAMH}$ was certainly the first association of its kind in East Africa and appears also to have been the first on the continent. ${ }^{98}$ The concept of a mental health association was not completely new: in 1956, Tewfik had established a Mental Hospitals Voluntary Association, which ran with a committee of five Europeans, five Asians and five Africans until Tewfik's departure in $1958 .{ }^{99}$ Yet while Tewfik's Association had focused primarily on bringing volunteer visitors into the mental hospital and giving comfort to the mentally ill, the NAMH was concerned with increasing public knowledge about mental health, improving the status of the mentally ill, and developing strategies for its prevention-the NAMH looked to the world outside the mental hospital, rather than in. ${ }^{100}$

The idea for the association had first been proposed by women associated with the medical community on Mulago hill, including Ethel Bosa (Bosa's first wife), Mrs. Kasirye (wife of J. W. S. Kasirye, then Medical Superintendent of Butabika Hospital), Harriet Kibukamusoke (wife of John Kibukamusoke, Professor of Medicine at Mulago Hospital and first African President of the Association of Physicians of East Africa) and Dorothy Wood (Wood's wife and German's sister). ${ }^{101}$ Ganda women in particular remained active in the early years of the association, reflecting an upsurge in social and political activism among women in central Uganda during the 1960s. ${ }^{102}$ By 1970, membership of the NAMH had reached 90, comprising, in addition to Ganda women, members of the Asian lay public.

For a brief period in the late 1960s and early 1970s, the NAMH was active in commissioning newspaper articles on mental illness for Taifa Empya, a Luganda newspaper. These attracted an enthusiastic response from Ugandan supporters of the Association, and by 1970, staff and students at Bishop Tucker College, Mukono, had translated articles into Karamajong, Runyankole and Luo-Lango. ${ }^{103}$ Members also organised seminars covering topics such as suicide, alcoholism, homosexuality and stigma. ${ }^{104}$ In a seminar entitled 'Suicide and the Law', held in December 
1970, Frank Farrelly, Consultant Psychiatrist, Butabika Hospital, presented alongside Justice Fuad, of the High Court, and Bishop Christopher Senyonjo. Fuad's paper, entitled 'Insanity and the Law', highlighted how while attempted suicide was still an offence in Uganda, the High Court had 'attempted to discourage prosecutions'. 105 Citing a judgement from 1965, Fuad noted that unless the accused required protection "“against himself" through a Probation Order, " "perhaps the modern approach" was to handle the issue outside of the courts entirely. ${ }^{106}$

Running alongside NAMH activities was a television programme, 'The Sick Mind', which consisted of a fortnightly forty-five-minute discussion between a psychiatrist-usually Bosa, German or Woodand a chairperson. These programmes, it was hoped, would disseminate 'basic knowledge about mental health to the lay public' and so reduce stigma. ${ }^{107}$ The show may have been modelled on a BBC series of five television programmes, broadcast in the UK in January 1957 under the title 'The Hurt Mind'. Yet while the BBC version included clips of psychiatrists interviewing patients about their experiences and staged demonstrations of electroconvulsive therapy and drug abreaction, ${ }^{108}$ no patients appeared on the Uganda programme. ${ }^{109}$ The popularity of the show, which was significant enough to keep the show on Uganda Television for five years, relied primarily on the personalities of those involved and the information presented by the psychiatrists. Topics reflected clinical diagnoses seen frequently at Butabika Hospital and Mulago Hospital Mental Health Clinic, including affective psychoses, schizophrenia, epilepsy, dementia and neurosyphilis. These topics, according to Wood, were surprisingly popular: 'following the episode discussing GPI and Syphilis the clinical laboratories were burdened by a huge increase in requests for Syphilis testing. ${ }^{110}$ While on a tour of Africa in 1968, George Burden, Secretary General of the International Bureau for Epilepsy, also participated in a discussion programme with Bosa. ${ }^{11}$ The use of this medium was pioneering - not only were specialists working in maternal and public health, traditionally the most innovative in health education campaigns, only just starting to experiment with television, but the Ministry of Health themselves complained in 19681969 that while television was 'fully open to us to use....We had neither actors nor films for showing'. ${ }^{112}$

'The Sick Mind' attempted to humanise psychiatry, making visible the psychiatrists who had previously been restricted to the mental hospital. While most Africans were unable to afford a television set, the Uganda 
Government, under Milton Obote, had pressed for the installation of large television screens in community centres across the country. While Obote's efforts were most likely prompted by political considerations, it had the effect of bringing educational programmes like 'The Sick Mind' to communities across Uganda. Certainly, German reported having the experience, 'on up-country clinic visits', of meeting patients and families who recognised him and his colleagues from his on-screen activities. ${ }^{113}$ Yet the 'public' they were trying to reach was still limited. Indeed, while at first Burden 'felt we were to be congratulated' on the programme made with Bosa, this fell away when he learned 'that not more than $2 \%$ of the population have a T.V. set and that we would have been wiser to have asked for a radio programme'. ${ }^{114}$ Indeed, it may have been such activities that Orley had in mind when he stressed that 'The job of mental health education is always hard. For every one success story told there may be several failures evident to all; added to which there are always plenty of lurid myths and rumours to dispel'. ${ }^{115}$

Whether or not 'The Sick Mind' succeeded in bringing a human face to psychiatry, it certainly politicised it. Shortly after Amin's takeover on 25 January 1971, the programme was moved to a new slot in a weekly production entitled 'Uganda Today', a weekly programme organised by Major Bob Astles, who later became notorious as 'the white rat of Uganda'. 116 The incorporation of this show may have been intended 'to show the Amin regime in a favourable light'. ${ }^{117}$ Amin himself was among the programme's viewers, having watched the show from The Uganda Club prior to his takeover. As German recalled: 'Apparently he liked it - and one evening, having been presented with a new Polaroid camera, he photographed me on the screen and sent me the photograph'. ${ }^{118}$ The photograph, which shows German mid-conversation, appears at first glance to be innocuous, but it could be read as an attempt at the kind of intimidation Amin became notorious for; as a sign that German, and by extension all of Uganda's psychiatrists, had come to the attention of Amin, and into a new political climate. ${ }^{119}$

\section{Patients}

Psychiatrists and those attached to the NAMH placed themselves firmly on the side of patients, extending ideas about mental health they believed would benefit the mentally ill and their families. They did not, however, give the patients themselves a voice. Nor was there any room for 
traditional medicine or healers. Indeed, both Ugandan and expatriate psychiatrists were openly ambivalent on the topic of traditional medicine: while most acknowledged that traditional healers could serve a useful function in remote areas, particularly with regard to psychoneuroses, they were concerned that traditional healers might cause real harm to their patients, and so had no place in 'modern' psychiatry. Joseph Muhangi later described the skill with which a wealthy and famous traditional healer had treated patients at Kasangati, near Kampala. This healer held sessions of 30-45 minutes, during which he saw a white female figure with whom he spoke in tongues. Having witnessed this, 'hysterical patients with paralysed limbs, women who were infertile because of psychological problems, and men with impotence of psychological origin...were subsequently able to use their limbs, have babies and recover their potency respectively'. ${ }^{120}$ Yet while Muhangi admitted that he was impressed by this, he also stressed that the healer was most likely epileptic, his technique merely 'psychodrama'. Bosa, too, questioned how some people could, on a Sunday morning, go to church, and in the evening visit a traditional healer, and certainly did not consider himself to be one of them. While he was open to the idea that his patients might derive benefits from visiting a traditional healer, he could never openly acknowledge it, lest he be seen to be practising or believing in traditional medicine. ${ }^{121}$

Bosa, like many other African doctors trained in the 1940s and 1950s, had been obliged to fight long and hard for recognition of his professional status, and setting himself apart as 'scientific' and 'modern' had been a vital part. ${ }^{122}$ Yet they could not have been ignorant of the fact that for most of their patients, traditional healers were their first and preferred choice in times of distress. Indeed, patients were frequently vocal during consultations with psychiatrists about the causes of their problems, and the methods of treatment that were appropriate. One 23-year-old Ismaili man, for example, had been referred to a psychiatric ward of a general hospital following a period in which he 'had been behaving oddly, waving his hands about and beating his wife'. ${ }^{123} \mathrm{He}$ told the psychiatrist that he felt himself being pulled by a long figure in a red cloth, and this was causing him to become frightened and violent. On one occasion, the patient explained, the man in the red cloth took him to a cemetery and made the dead come alive, saying: 'I will make you like this. I will put you in a grave and bury you there'. ${ }^{124}$ Certain that he had been bewitched, he told the psychiatrist that psychiatric medication would be useless, including electroconvulsive therapy. Instead, he would 
seek treatment from a young Ismaili woman, who would capture the spirit, reduce its size and burn it. The patient's role would be to pray and to attend the mosque for forty days. ${ }^{125}$

The distinction between 'modern' and 'anti-modern' practices in psychiatry was not one that was limited to the African context, but it took on particular significance given the scale of the cultural and political gulf between psychiatrists and their patients. Instead of seeking to use traditional healers as potential psychiatric 'allies' in a context where personnel was thin on the ground, it was made clear that a patient at Butabika might only be granted a period of leave to return home to consult a traditional healer with the permission of a psychiatrist. ${ }^{126}$ It is questionable how frequently patients were allowed to do this, however, and there is evidence to suggest that some psychiatrists were not averse to attempting to alter 'traditional' beliefs they felt might be dangerous to the mental health of their patients. Orley, for example, was keen to promote the value of local understandings of mental illness in Buganda not only to assist in diagnosis, but also to suggest to patients alternative ways of looking at their own mental health. 'If one has some idea of the beliefs about an illness', Orley wrote in 1970, 'it is possible at times to modify them somewhat and to create new beliefs that may be more beneficial to the patient'. ${ }^{127}$ Akawango, for instance, comprising a persistent headache, was of concern to patients because it indicated a potential 'spoiling' of the brain, 'and the anxiety resulting from such a belief can make things even worse'. As the name was derived from the word ekiwanga, however, meaning 'the skull', it would be possible for practitioners to explain, while giving medication, that the illness was limited to the bone, rather than the brain. ${ }^{128}$ While Orley believed this was in the best interests of his patients, it nevertheless had ethical implications. 'A more dubious procedure', Orley continued, 'which I have used successfully in cases of epilepsy, is to tell the relatives of a patient that the tablets prevent the illness spreading to others, and so the patient need no longer be isolated. When it is seen that the tablets do in fact prevent fits as forecast, then the assumption is that the statement about the illness being no longer infectious is also true'. ${ }^{29}$ This, Orley noted, was justified because it might help reduce the number of patients being subjected to 'enforced isolation' within communities. ${ }^{130}$

While traditional healers and ideas about mental illness were not given any formal place at Butabika, assumptions about the importance of 'community' in the treatment of mental illness nevertheless started to 
inform rehabilitation activities. Rhythm and drumming were encouraged among patients. ${ }^{131}$ Group psychotherapy was also introduced among selected patients in 1968. On the one hand, this was premised on the desire to draw on the 'therapeutic potential' of less qualified hospital staff, such as nurses and ward sisters, to ensure that treatment went beyond solely physical therapies; ${ }^{132}$ on the other, it was argued elsewhere in Africa that using groups brought psychiatry closer to the traditional 'social fabric' of African life. ${ }^{133}$ The groups were unorthodox in the sense that 'gaining insight' was not emphasised, but they provided a forum in which patients could discuss how a ward could deal with a particularly disruptive patient, how patients would be greeted on their return home, and comparisons of 'European' and 'African' treatment. ${ }^{134}$ In this, the role of the hospital staff, as Ugandans, was deemed to be key. As Wood explained, while they had no formal knowledge of 'psychology as a science...they live in a community and have experience of human relationships', they speak the same languages as the patients and 'are surprisingly interested in the patients' welfare', spending the most time with them on the wards. As with medical assistants, they were deemed to be particularly valuable to psychiatry because they were regarded as occupying a social and cultural space that was much closer to their patients than the psychiatrists.

Many of the reforms put in place at Butabika Hospital in the late 1960s and early 1970s aimed to extend the power of psychiatry through the staff who oversaw the day-to-day running of the hospital. Yet this did not render patients powerless within the institution. Many demonstrated their importance and independence by complaining about the quality of the food, expressing scepticism about the value of being required to talk constantly about their lives and anxieties, and negotiating medication and trips into Kampala to conduct small business deals. ${ }^{135}$ Nakuzabasajja, for example, a 42-year-old cultivator and businessman from a small town beyond Kampala, frequently declared that he was being treated as a prisoner and rejected medication (saying there were too many tablets), as well as food, unless it was brought by his family from home. ${ }^{136}$ When, after a stay of ten weeks, he was discharged from Butabika Hospital, he continued to resent what he regarded as unwanted attention from psychiatry. During a visit from a PSW, he became angry, stating that, as 'a government employee', the social worker had no business 'in my family affairs'. ${ }^{137}$ After a few weeks, Nakuzabasajja wrote to the hospital, describing his suffering while in hospital, and making it clear that 
he would not return or take any more medication. Instead, he would remain at home, concentrating on his business, and seek assistance from traditional healers. ${ }^{138}$ What such cases suggest is that when patients did co-operate, or build relationships with hospital staff, they had their own motivations for doing so.

\section{Conclusion}

Medical practitioners have described the years immediately leading up to Amin's expulsion of the Asian population in 1972 as something of a 'golden age' for psychiatry in Uganda. Writing in 1985, Bennett described Uganda as 'one of the countries in Africa with the most effective and innovative programmes for control of mental illness'. ${ }^{139} \mathrm{He}$ listed research that had been undertaken into the epidemiology of maternal mental illness, child psychiatry and the mental health problems of university students. He also highlighted training programmes in psychiatry and psychology available for medical students and psychiatric nurses. ${ }^{140}$ Looking beyond the university, Orley claimed in 1970 that Butabika Hospital is now regarded as the natural replacement for the stocks of old. It is rare in these days to see patients shackled, although they are often tied with rope'. ${ }^{141}$ Such was the importance of the institution, Orley asserted, that 'the immediate reaction to anyone who shows signs of what is thought to be unreasonable violence is to try to get them to Butabika Hospital, and while there is any sign that this behaviour might recur, the family are extremely reluctant to take the patient back home'. ${ }^{142}$

Certainly, the late 1960s and early 1970s saw a brief period of intense activity in psychiatry, characterised by attempts to extend the reach of mental health care through the training of auxiliaries, as well as educational activities aimed at the wider, if still limited, Ugandan public. In doing so, psychiatrists went well beyond their custodial and curative roles. Their actions were premised on a belief that psychiatry and psychiatric expertise could assist in improving mental health and well-being, as well as a conviction that psychiatrists could contribute their expertise to issues of social planning and national development. In turn, this culture of experimentation was not only made possible by a period of relative calm in Uganda's history, but a new sociopolitical context that encouraged innovation. Psychiatry responded and tried to contribute to the aims of the developmentalist state not only through interest in education and urbanisation, but by putting manpower needs at the centre of 
calls for reform. As Obote stressed in his Foreword to the First Five-Year Development Plan, the government's strategy 'will not work unless the people grasp the opportunity offered and participate wholeheartedly in this great task of economic and social development of the country. In the first and last analysis, the country's development is dependent on the people themselves'. ${ }^{143}$ While psychiatrists remained subordinate to government officials, who in turn had their own concerns and priorities-not least finances, hierarchy and the maintenance of political control-the 1960s and early 1970s signalled an attempt to refigure the relationship between psychiatry and the Ugandan people, as well as the broader place of psychiatry within the nation. The mental hospital may have continued to represent the centre of psychiatric practice, and the only real institution available to the state for dealing with individuals certified as insane, but psychiatry now looked to mobilise other professionals in support of mental health care. While psychiatry had long relied on other professionals, notably the police and the judiciary, psychiatrists now sought to change ideas and practices, and to use them to extend the reach of psychiatry.

For all the rhetoric of change and success, there remained a large gap between intentions and 'on the ground' practices. The processes of admission, diagnosis and treatment remained haphazard and continued to follow the same patterns as they had under colonial rule. Until well into the 1970s at least, violence and proximity to the mental hospital remained the most common reasons for admission. Patients, too, continued to make decisions about their own lives and the types of treatment they believed were appropriate. Even among the new generation of psychiatric auxiliaries, the ability of psychiatrists to change ideas may have been limited. In a study examining the effect of psychiatric education on attitudes to illness among the Ganda, Orley and J. P. Leff, a psychiatrist based at the Medical Research Council, London, found that while educated urban Ugandans still held onto Ganda conceptions of mental illness as 'strong', coming from witchcraft or the actions of spirits, and not treatable through Western medicine, 'by the end of a course of psychiatric nursing these traditional constructs have virtually been abandoned'. ${ }^{144}$ 'The most likely interpretation', however, was that 'the small group of people who opt for psychiatric nursing are highly self-selected and are already less traditional in their attitude to illness than the rest of the population'. As a result, they concluded, it was likely that 'the effect 
of medical education in changing traditional attitudes to illness may well appear disappointingly small'. ${ }^{145}$

While the effects of the psychiatric reforms of the late 1960s and early 1970s may have been limited within Uganda, the sense of shared challenges among psychiatrists in rapidly decolonising countries proved a unifying force across borders. Increasingly through the 1960s, Uganda's psychiatrists shared their approaches in journals such as Psychopathologie Africaine, and took part in transnational and international exchanges that aimed at developing ideas and practices on mental health care in the light of the contextually specific needs of newly independent African countries. During the 1968-1969 academic year, for example, visitors to the Department of Psychiatry included J. C. Likimani (Director of Mental Services, Kenya), A. Boroffka (Nigeria), R. Giel (Ethiopia), A. Howarth (Zambia), T. Baasher (Sudan), C. R. Swift (Tanzania) and C. C. Adomakoh (Ghana). ${ }^{146}$ In the years following the establishment of Medical Faculties at the University of East Africa Colleges in Kenya and Tanzania, psychiatrists attached to Makerere also offered advice and expertise on curriculum development and became involved in the search for professorial heads and visiting lectureships. ${ }^{147}$ At such meetings, the question of how best to organise mental health services in developing countries would come to dominate discussions, eventually being taken up as a key WHO concern.

\section{Notes}

1. G. A. German, 'The Psychiatry of Poverty', Psychopathologie Africaine 7(1) (1971), p. 113.

2. Ibid.

3. M. M. Heaton, Black Skin, White Coats: Nigerian Psychiatrists, Decolonization, and the Globalization of Psychiatry (Ohio, 2013).

4. M. I. Assael et al., 'Psychiatric Disturbances During Pregnancy in a Rural Group of African Women', Social Science \& Medicine 6(3) (1972), p. 394. On Kasangati Health Centre, see F. J. Bennett, G. A. Saxton, and A. Mugalula-Mukiibi, 'Kasangati-The Background to a Health Centre', in F. J. Bennett, ed., Nkanga: Special Edition on Medicine and Social Sciences in East and West Africa (Kampala, 1973).

5. J. L. Cox, 'Psychiatric Morbidity and Childbirth: A Prospective Study from Kasangati Health Centre, Kampala', Proceedings of the Royal Society of Medicine 69(3) (1976), pp. 221-222. 
6. H. G. Egdell and J. P. Stanfield, 'Paediatric Neurology in Africa: A Ugandan Report', British Medical Journal (February 1972), pp. 548-552.

7. G. A. German, 'Aspects of Clinical Psychiatry in Sub-Saharan Africa', The British Journal of Psychiatry 121(564) (1972), pp. 461-479; C. A. Leon, 'Psychiatry in Latin America', The British Journal of Psychiatry 121(561) (1972), pp. 121-236; J. S. Neki, 'Psychiatry in South-East Asia', The British Journal of Psychiatry 123(574) (1973), pp. 257-269.

8. German, 'Aspects of Clinical Psychiatry', p. 477.

9. Ibid.

10. G. M. Carstairs, 'Psychiatric Problems of Developing Countries', The British Journal of Psychiatry 123(574) (1973), p. 272.

11. J. Hall, 'Some Aspects of Economic Development in Uganda', African Affairs 51(203) (1952), pp. 124-134; R. Reid, A History of Modern Uganda (Cambridge, 2017), p. 234.

12. A. B. K. Kasozi, The Social Origins of Violence in Uganda, 1964-1985 (Montreal, 1994), p. 47.

13. A. Burton and M. Jennings, 'Introduction: The Emperor's New Clothes? Continuities in Governance in Late Colonial and Early Postcolonial East Africa', International Journal of African Historical Studies 40(1) (2007), pp. 13-14.

14. Uganda Government, The First Five-Year Development Plan (Entebbe, $1962)$, pp. $42,44$.

15. D. M. Anderson and R. Rathbone, "Urban Africa: Histories in the Making', in D. M. Anderson and R. Rathbone, eds., Africa's Urban Past (Oxford, 2000).

16. Mental Health Services in the Developing World: Reports on Workshops on Mental Health, Edinburgh (1968) and Kampala (1969), Commonwealth Foundation Occasional Paper, IV (Hove, 1969), p. 31.

17. Mental Health Services in the Developing World, p. 32.

18. C. Sicherman, Becoming an African University: Makerere, 1922-2000 (Trenton, 2005), p. 153.

19. Reid, A History of Modern Uganda, p. 253.

20. J. C. Ssekamwa, History and Development of Education in Uganda (Kampala, 2000), Ch. 12.

21. A. Burton, 'The Haven of Peace Purged: Tackling the Undesirable and Unproductive Poor in Dar es Salaam, ca.1950s-1980s', International Journal of African Historical Studies 40(1) (2007), pp. 119-151.

22. F. J. Bennett, 'The Mental Health of African Students in Africa' (Unpublished Paper, 1967), as summarised in G. A. German and O. P. Arya, 'Psychiatric Morbidity Amongst a Uganda Student Population', The British Journal of Psychiatry 115 (1969), pp. 1323-1329.

23. German and Arya, 'Psychiatric Morbidity', p. 1323. 
24. Ibid., p. 1324.

25. O. P. Arya and F. J. Bennett, 'Venereal Disease in an Elite Group (University Students) in East Africa', British Journal of Venereal Diseases 43 (1967), pp. 275-279.

26. German and Arya, 'Psychiatric Morbidity', p. 1328.

27. R. Prince, 'The "Brain Fag" Syndrome in Nigerian Students', Journal of Mental Science 106 (1960), p. 559.

28. German and Arya, 'Psychiatric Morbidity', p. 1327. See also, G. A. German and M. I. Assael, 'Achievement Stress and Psychiatric Disorders Amongst Students in Uganda', Israel Annals of Psychiatry and Related Disciplines 9(1) (1971), p. 33.

29. F. J. Bennett and A. Mugalula-Mukiibi, 'An Analysis of People Living Alone in a Rural Community in East Africa', Social Science \& Medicine 1 (1967), pp. 97-115.

30. Uganda Government, The First Five-Year Development Plan, p. 2.

31. F. J. Bennett and M. I. Assael, 'The Mental Health of Immigrants and Refugees from Rwanda at Kasangati, Uganda', Psychopathologie Africaine 6(3) (1970), p. 322. See also, K. Long, 'Rwanda's First Refugees: Tutsi Exile and International Response 1959-64', Journal of Eastern African Studies 6(2) (2012), pp. 211-229.

32. Bennett and Assael, 'The Mental Health of Immigrants', p. 327.

33. Ibid., p. 326.

34. Ibid., p. 332.

35. A. M. Mazrui, Political Values and the Educated Class in Africa (Berkeley and Los Angeles, 1978), p. 254.

36. C. Sicherman, 'Ngugi's Colonial Education: “The Subversion... of the African Mind"', African Studies Review 38(3) (1995), pp. 11-41.

37. B. Lindfors, ed., Africa Talks Back: Interviews with Anglophone African Authors (Trenton, NJ, 2002), p. 197.

38. R. Bridges and M. Posnansky, 'African History at Makerere in the 1960s:

A Further Perspective', History in Africa 31 (2004), pp. 479-482;

C. Sicherman, Becoming an African University.

39. J. Nagenda, 'And This, At Last', in D. Cook, ed., Origin East Africa: A Makerere Anthology (London, 1965), p. 26.

40. J. Kariara, 'The Dream of Africa', in Cook, ed., Origin East Africa, p. 100.

41. Bennett and Assael, 'The Mental Health of Immigrants'; Bennett and Mugalula-Mukiibi, 'An Analysis of People Living Alone'.

42. Arya and Bennett, 'Venereal Disease in an Elite Group'.

43. German and Arya, 'Psychiatric Morbidity'.

44. D. W. Dunlop, 'Health Care Financing: Recent Experience in Africa', Conference paper delivered at 'Health and Development in Africa', University of Bayreuth, Germany, 2-4 June 1982, p. 13. 
45. Uganda Ministry of Health Archives (UMOHA) (First and Second FiveYear Development Plans-1961/66 and 1966/71), 'Achievements', 23 April 1968, p. 1.

46. As cited in J. Iliffe, East African Doctors: A History of the Modern Profession (Kampala, 2002), p. 137.

47. UMOHA PH/ASC/42, Box 56, Old Arrangement (Mental Health Advisory Committee: Association), f. 1, 'Recommendations of the Mental Health Advisory Committee on Up-Country Psychiatric Units', October 1967, p. 3

48. Ibid., p. 1.

49. Personal communication with G. A. German, 29 January 2012.

50. UMOHA PH/ASC/42, f. 6, 'Minutes of the Mental Health Advisory Committee Meeting held on 11 August 1971 in Mulago Hospital Board Room at 2.15 p.m.'.

51. UMOHA PH/ASC/42, E. B. Ssekabembe, 'Report on the Mental Health Follow Up Clinic at Jinja by Dr. Ssekabembe', n.d.; UMOHA $\mathrm{PH} / \mathrm{ASC} / 42$, S. B. Bosa and F. J. Harris, 'Memorandum on the Function, Training \& Recruitment of Psychiatric Social Workers \& Mental Health Assistants in Uganda', no date; and UMOHA PH/ ASC/42, H. G. Egdell, 'Interpreters \& the Uganda Psychiatric Service', 7 October 1968.

52. UMOHA PH/ASC/42, f. 3, 'Minutes of the 11 th Meeting of the Mental Health Advisory Committee held on 24 June 1969', p. 1.

53. UMOHA PH/ASC/42, Egdell, 'Interpreters', 7 October 1968.

54. Ibid.

55. UMOHA PH/ASC/42, f. 3, 'Minutes of the 1 lth Meeting of the Mental Health Advisory Committee held on 24 June 1969', p. 1.

56. UMOHA PH/ASC/42, 'Memorandum on the Function, Training \& Recruitment of Psychiatric Social Workers \& Mental Health Assistants in Uganda'.

57. UMOHA PH/ASC/42, f. 2, 'Minutes of the 9th Meeting of the Mental Health Advisory Committee held on 29 October 1968', p. 2.

58. UMOHA PH/ASC/42, 'Report on the Mental Health Follow Up Clinic at Jinja by Dr. Ssekabembe', p. 1 .

59. UMOHA PH/ASC/42, S. Beyo Bosa, 'Report on the Development and Functioning of the Psychiatric Clinic at Mbarara Hospital, Ankole District', n.d. (likely 1969), p. 2.

60. Ibid., p. 3.

61. Personal communication with German.

62. UMOHA C90/ACR (Bosa Stephen B-Consult. Psychiat.), f. 113, letter from J. Bulwanyi, Medical Superintendent, to The Permanent Secretary/Chief Medical Officer, Entebbe, 3 April 1967. 
63. J. Orley, 'A Prospective Study of 372 Consecutive Admissions to Butabika Hospital, Kampala', East African Medical Journal 49(1) (1972), p. 18.

64. UMOHA C90/ACR, f. 127, letter from Y. K. Lule, Principal, Makerere University College, to I. S. Kadama, Chief Medical Officer, Entebbe, 27 July 1968.

65. F. J. Bennett, 'Medical Manpower in East Africa: Prospects and Problems', East African Medical Journal 42(4) (1965), pp. 149-161.

66. H. G. Egdell, 'The Medical Assistant and Psychiatric Care', Psychopathologie Africaine 6 (1970), p. 83.

67. UMOHA PH/ASC/42, 'Memorandum on the Training of Medical Assistants in Psychiatry', 24 June 1969.

68. Egdell, 'The Medical Assistant', p. 83.

69. Ibid.

70. Ibid., p. 85 .

71. UMOHA PH/ASC/42, 'Memorandum on the Training of Medical Assistants in Psychiatry', 24 June 1969.

72. UMOHA PH/ASC/42, f. 3 , 'Minutes of the 11 th Meeting of the Mental Health Advisory Committee Held on 24 June 1969', p. 2.

73. UMOHA PH/ASC/42, S. Beyo Bosa, 'Report on the Development and Functioning of the Psychiatric Clinic at Mbarara Hospital, Ankole District', n.d. (likely 1969), p. 3; UMOHA PH/ASC/42, 'Report on the Mental Health Follow Up Clinic at Jinja by Dr. Ssekabembe', p. 1.

74. UMOHA $\mathrm{PH} / \mathrm{ASC} / 42$, 'Memorandum on the Training of Medical Assistants in Psychiatry', 24 June 1969.

75. UMOHA PH/ASC/42, f. 6, 'Minutes of the Mental Health Advisory Committee Meeting Held on 11 August 1971 in Mulago Hospital Board Room at 2.15 p.m.', p. 1 .

76. Interview with female nurse (RUK-10), Rwakabengo, Rukungiri, 5 July 2011.

77. Orley, 'A Prospective Study', p. 21.

78. Ibid., p. 18.

79. J. F. Wood, 'A Half Century of Growth in Ugandan Psychiatry', Uganda Atlas of Disease Distribution (Kampala, 1968), p. 121.

80. 'Question 18 of 1970, 21 April 1970', Uganda Hansard, 99, Fourth Session (1970/1971), pp. 18-20.

81. J. F. Wood, 'An Introduction to the Uganda Psychiatric Service' (Unpublished lecture, copy in possession of author, 1969).

82. J. F. Wood, 'Psychiatry for Lawyers' (Unpublished lecture, copy in possession of author, 1970).

83. Wood, 'Psychiatry for Lawyers'. 
84. Wood, 'Psychiatry for Lawyers'; Roger Davidson, 'Psychiatry and Homosexuality in Mid-Twentieth-Century Edinburgh: The View from Jordanburn Nerve Hospital', History of Psychiatry 20(4) (2009), p. 417.

85. B. J. F. Laubscher, Sex, Custom and Psychopathology: A Study of South African Pagan Natives (London, 1937); A. H. Leighton et al., eds., Psychiatric Disorders Among the Yoruba: A Report from the Cornell-Aro Mental Health Research Project in the Western Region, Nigeria (Ithaca, NY, 1963), p. 111; C. G. F. Smartt, 'Mental Maladjustment in the East African', British Journal of Mental Science 102 (1956), p. 442; W. H. Watson, 'A Case of Sexual Perversion in an African Male', East African Medical Journal 20(10) (1943), p. 354. On psychiatry and homosexuality in South Africa, see T. F. Jones, Psychiatry, Mental Institutions, and the Mad in Apartheid South Africa (Abingdon, 2012), Ch. 7.

86. German and Arya, 'Psychiatric Morbidity', pp. 1323-1329.

87. On the history of attitudes to homosexuality, see K. Cheney, 'Locating Neocolonialism, "Tradition," and Human Rights in Uganda's "Gay Death Penalty"', African Studies Review 55(2) (2012), pp. 77-95; N. Hoad, African Intimacies: Race, Homosexuality, and Globalization (Minneapolis, 2007), Ch. 1; S. Tamale, 'Out of the Closet: Unveiling Sexuality Discourses in Uganda', in C. M. Cole, T. Manuh, and S. F. Miescher, eds., Africa After Gender (Bloomington, IN, 2007), p. 10.

88. CAP 302, The Penal Code Act (Entebbe, 1950).

89. Uganda Protectorate, Annual Report of the Judiciary for the Year Ended 31 st December, 1960 (Entebbe, 1961), p. 2.

90. Wood, 'Psychiatry for Lawyers'.

91. Wood, 'Psychiatry for Lawyers'.

92. D. L. Davies, 'Report on the Teaching of Psychiatry at Makerere University College Department of Psychiatry' (Unpublished report, copy in possession of author, 1969); Personal communication with German.

93. Wood, 'An Introduction to the Uganda Psychiatric Service'.

94. Personal communication with J. F. Wood, 7 October 2011.

95. Wood, 'An Introduction to the Uganda Psychiatric Service'.

96. Mental Health Services in the Developing World, p. 43.

97. Personal communication with German; 'Department of Psychiatry Annual Report, 1968-1969', Makereve University College Reports, 19681969 (Kampala, copy in possession of author, 1969).

98. Kenya, for example, did not start a National Mental Health Association until 1986. World Health Organization Library (WHOL) MNH/ POL/87.3, Tenth Meeting of the African Mental Health Action Group, Geneva, 8 May 1987, p. 5.

99. Bodleian Library, University of Oxford (BOD) Micr.Afr.609(2) (Papers of J. N. P. Davies), 'Mental Hospital Annual Report, 1956', p. 5; G. I. Tewfik, 'A Hospital Visitors' Association', The Lancet (October 1956), p. 834.

100. UMOHA PH/ASC/42. 
101. Personal communication with German.

102. A. M. Tripp, Women and Politics in Uganda (Oxford, 2000), Ch. 2.

103. UMOHA PH/ASC/42, 'Notes from the Chairman's Report to the A.G.M.', 5 December 1970; Personal communication with German.

104. UMOHA PH/ASC/42, 'Uganda National Association for Mental Health membership form', n.d.

105. J. Fuad, 'Insanity and the Law' (Unpublished seminar paper, copy in possession of author, 1970).

106. Fuad, 'Insanity and the Law'.

107. 'Department of Psychiatry Report, 1966-1967', Makerere University College Reports, 1966-1967 (Kampala, copy in possession of author, 1967); Personal communication with German. On Uganda Television see Abraham Z. Bass, 'Promoting Nationhood Through Television in Africa', Journal of Broadcasting 13(2) (1969), p. 164; Deborah Haskell, 'Educational Television in Uganda', Today's Speech 19(4) (1971), pp. 43-49.

108. G. M. Carstairs and J. K. Wing, 'Attitudes of the General Public to Mental Illness', British Medical Journal (6 September 1958), pp. 594597. A selection of clips from this series is available on YouTube: British Broadcasting Corporation, 'Physical Mental Health Treatments 1957, Part 1', last accessed 12 December 2012, at http://www.youtube.com/ watch? $\mathrm{v}=2 \mathrm{KxU} 3 \mathrm{dPeink}$.

109. Personal communication with Wood.

110. Personal communication with Wood.

111. World Health Organization Archives (WHOA) M4/348/1 (General Information re: Relations with Mental Health Organisations, Jkt 1), f. 73, George Burden, 'Africa Revisited-December 1968', p. 3.

112. UMOHA GCH $9 / 2$ (Health Education), f. 140(2), 'Plan of Work for Health Education Unit of Ministry of Health Basis for Wider Planning', 1969 , p. 3; F. J. Bennett and H. Senkatuka, 'Health Education Via Mass Media', Journal of Tropical Pediatrics 12(supp3) (1966), pp. 31-32.

113. Personal communication with German.

114. WHOA M4/348/1, f. 73, Burden, 'Africa Revisited', p. 3.

115. Orley, Culture and Mental Illness, p. 57.

116. Personal communication with German; Haskell, 'Educational Television'. On Astles, see 'Obituaries: Bob Astles', The Times, 23 January 2013; Paul Vallely, 'I Genuinely Felt That by Being There I Could Moderate His Excesses', The Times, 10 December 1985, p. 5.

117. Personal communication with German.

118. Personal communication with German.

119. On Amin's use of the media see Patrick Keatley, 'Obituary: Idi Amin', The Guardian, 18 August 2003; D. R. Peterson and E. C. Taylor, 'Rethinking the State in Idi Amin's Uganda: The Politics of Exhortation', Journal of Eastern African Studies 7(1) (2013), pp. 58-82. 
120. J. Muhangi, 'Psychiatry in Kenya: New Horizons in Medical Care', Inaugural lecture delivered at the University of Nairobi, 31 January 1980, pp. 15-16.

121. Personal communication with Joseph Bossa, 6 July 2012.

122. Iliffe, East African Doctors, Ch. 5. Much of this fight can be traced through UMOHA PH/ASC/46 (Box 29) (Makerere Medical Graduates Association).

123. F. J. Harris, Social Casework: An Introduction for Students in Developing Countries (Nairobi, 1970), p. 161.

124. Ibid.

125. Ibid., pp. 160-165.

126. Personal communication with German; Personal communication with Wood.

127. Orley, Culture and Mental Illness, p. 52.

128. Ibid.

129. Ibid., p. 53.

130. Ibid.

131. Personal communication with Wood.

132. J. F. Wood, 'Utilising Therapeutic Potential in Psychiatric Hospital Staff', Psychopathologie Africaine 6(3) (1970), p. 301. The importance of small social groups is also emphasised in J. F. Wood, 'Rehabilitation \& Psychiatry' (Unpublished lecture, copy in possession of author, n.d.).

133. E. Corin and H. B. M. Murphy, 'Psychiatric Perspectives in Africa Part I: The Western Viewpoint', Transcultural Psychiatry 16(2) (1979), p. 168; T. A. Lambo, 'Psychotherapy in Africa', Psychotherapy and Psychosomatics 24(4-6) (1974), pp. 311-326.

134. Lambo, 'Psychotherapy in Africa', pp. 312, 314.

135. Harris, Social Casework.

136. Ibid., pp. 142-149.

137. Ibid., p. 148.

138. Ibid., p. 146.

139. F. J. Bennett, as cited in C. P. Dodge and P. D. Wiebe, eds., Crisis in Uganda: The Breakdown of Health Services (Oxford, 1985), p. 50.

140. Ibid.

141. Orley, Culture and Mental Illness, p. 30.

142. Ibid., p. 41.

143. Uganda Government, First Five Year Development Plan, Foreword.

144. J. H. Orley and J. P. Leff, 'The Effect of Psychiatric Education on Attitudes to Illness Among the Ganda', The British Journal of Psychiatry $121(2)$ (1972), p. 140.

145. Ibid.

146. 'Department of Psychiatry Report, 1968-1969'.

147. Personal communication with German. 
Open Access This chapter is licensed under the terms of the Creative Commons Attribution 4.0 International License (http://creativecommons.org/licenses/ by $/ 4.0 /$ ), which permits use, sharing, adaptation, distribution and reproduction in any medium or format, as long as you give appropriate credit to the original author(s) and the source, provide a link to the Creative Commons license and indicate if changes were made.

The images or other third party material in this chapter are included in the chapter's Creative Commons license, unless indicated otherwise in a credit line to the material. If material is not included in the chapter's Creative Commons license and your intended use is not permitted by statutory regulation or exceeds the permitted use, you will need to obtain permission directly from the copyright holder.

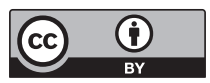

